\begin{tabular}{|c|c|}
\hline Title & Flexible C-C Bonds: Reversible Expansion, Contraction, Formation, and Scission of Extremely Elongated Single Bonds \\
\hline Author(s) & Shimajiri, T akuya; Suzuki, Takanori; Ishigaki, Y usuke \\
\hline Citation & $\begin{array}{l}\text { A ngewandte chemie international edition, 59(49), 22252-22257 } \\
\text { https://doi.org/10.1002/anie.202010615 }\end{array}$ \\
\hline Issue Date & $2020-12-01$ \\
\hline Doc URL & http://hdl.handle.net/2115/83376 \\
\hline Rights & $\begin{array}{l}\text { This is the peer reviewed version of the following article: A ngewandte Chemie (International ed.) 59(49) December } 1 \text {, } \\
2020 \text { pp.22252-22257 } \\
\text {, which has been published in final form at https://doi.org/10.1002/anie.202010615. This article may be used for non- } \\
\text { commercial purposes in accordance with Wiley Terms and Conditions for U se of Self-A rchived V ersions. }\end{array}$ \\
\hline Tyре & article (author version) \\
\hline File Information & A ngew. Chem.-Int. Edit.59-49_22252-22257.pdf \\
\hline
\end{tabular}

Instructions for use 


\title{
Flexible C-C Bonds: Reversible Expansion, Contraction, Formation, and Scission of Extremely Elongated Single Bonds
}

\author{
Takuya Shimajiri, ${ }^{[a]}$ Takanori Suzuki, ${ }^{[a]}$ and Yusuke Ishigaki*[a]
}

[a] T. Shimajiri, Prof. Dr. T. Suzuki, Dr. Y. Ishigaki
Department of Chemistry, Faculty of Science
Hokkaido University
Sapporo 060-0810 (Japan)
E-mail: yishigaki@sci.hokudai.ac.jp
Supporting information for this article is given via a link at the end of the document.

\begin{abstract}
Since carbon-carbon $(\mathrm{C}-\mathrm{C})$ covalent bonds are rigid and robust, the bond length is, in general, nearly constant and depends only on the bond order and hybrid orbitals. We report here direct visualization of the reversible expansion and contraction of a Csp ${ }^{3}$ $\mathrm{Csp}^{3}$ single bond by light and heat. This flexibility of a C-C bond was demonstrated by X-ray analyses and Raman spectroscopy of hexaphenylethane (HPE)-type hydrocarbons with two spirodibenzocycloheptatriene units, where intramolecular [2+2] photocyclization and thermal cleavage of the resulting cyclobutane ring both occur in a single-crystalline phase. The force constant of the contracted $\mathrm{C}-\mathrm{C}$ bond is 1.6 times greater than that of the expanded bond. Since formation of the cyclobutane ring and contraction of the $\mathrm{C}-\mathrm{C}$ bond lower the $\mathrm{HOMO}$ level by ca. $1 \mathrm{eV}$, the oxidative properties of these HPEs having a flexible $\mathrm{C}-\mathrm{C}$ bond can be deactivated/activated by light/heat.
\end{abstract}

\section{Introduction}

Carbon-carbon (C-C) covalent bonds represent the most fundamental concept in organic chemistry. Elucidation of their nature is of great importance for further understanding of chemical phenomena; for instance, to understand what happens at the limits of a bond. Since deviation from the standard causes a large loss of bonding energy, structural parameters such as bond length and bond angle are nearly constant among carbon atoms. However, strained molecules such as stericallycongested polycyclic aromatic hydrocarbons ${ }^{[1-8]}$ as well as cyclic $\pi$-conjugated compounds ${ }^{[9-15]}$ exhibit unusual parameters, and thus have attracted much attention due to their potential applications. With regard to the $\mathrm{C}-\mathrm{C}$ single bond, which has a standard length of $1.54 \AA$, three approaches have been taken to increase the bond length in neutral organic compounds to beyond $1.7 \AA$ : (i) diamondoid dimers, ${ }^{[16]}$ (ii) fused or clamped hexaphenylethanes (HPEs), ${ }^{[1-19]}$ and (iii) diaminocarboranes (Figure 1). ${ }^{[20]}$ Among these, we focused on the second approach (ii) while adopting the core-shell strategy, which enables the isolation of stable dispiro[dibenzocycloheptatriene (DBCHT)]type HPEs 1 with an extremely elongated $\mathrm{Csp}^{3}-\mathrm{Csp}^{3}$ bond [1.806(2) $\AA$ for $1 \mathrm{c}$ at $400 \mathrm{~K}]$. We envisaged that such a "hyper covalent bond" should be weak enough to exhibit reversible expansion, contraction, formation, and scission, which could be visualized by $\mathrm{X}$-ray analyses.
The key point is the DBCHT unit, which has been used to construct photoresponsive molecules based on overcrowded ethylenes through syn/anti isomerization. ${ }^{[21,22]}$ Another aspect is a structurally fixed cis-stilbene moiety in the DBCHT unit, and thus the intramolecular [2+2] cycloaddition reaction could proceed as in DBCHT-dimer to produce a caged molecule. ${ }^{[23]}$ The latter reactivity is more interesting from a topochemical point of view, since the solid-state reaction would be applicable for stimuli-responsive systems toward potential applications such as photoswitching, optical recording, and sensing materials. ${ }^{[24-32]} \mathrm{By}$ controlling the crystal packing structure, intermolecular [2+2] cyclization could proceed in a single-crystal-to-single-crystal (SCSC) manner upon photoirradiation, which has been realized by the aid of soft matter/lattices such as ionic crystals, metalorganic frameworks, and coordination polymers. ${ }^{[33-38]}$ Furthermore, only a few examples exhibit reversible SCSC photocycloaddition and thermal cleavage of a cyclobutane ring, ${ }^{[34-36]}$ and none of them are pure neutral organic molecules. (i)

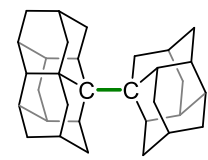

Schreiner et al. [16] in 2011 (iii) $\mathrm{RH}_{2} \mathrm{C}-\mathrm{NH} \quad \mathrm{HN}-\mathrm{CH}_{2} \mathrm{R}$

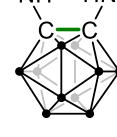

$\mathrm{R}=$ mesityl

- $=\mathrm{BH}$

Xiao et al. ${ }^{[20}$

in 2019 (ii)

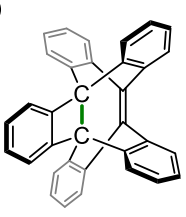

Herges et al. [17] in 1997

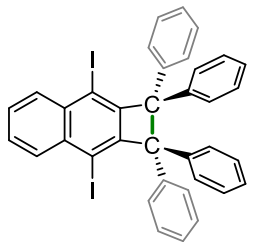

Toda et al. ${ }^{[18]}$ in 2001

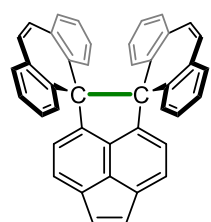

spiro-DBCHT 1c ${ }^{[19]}$ in 2018
Figure 1. Previously reported molecules. Three approaches have been used to make compounds with an elongated $\mathrm{C}-\mathrm{C}$ bond, which is surrounded only by (i) $\mathrm{sp}^{3}$-hybridized carbons, (ii) $\mathrm{sp}^{2}$-hybridized carbons, or (iii) heteroatoms.

Since cis-stilbene moieties connected by an elongated $\mathrm{C}-\mathrm{C}$ bond face each other in the outer 'shell'-structure of 
dispiro(DBCHT)-type HPEs 1a-1c, we expect that a reversible SCSC [2+2] photocycloaddition and thermal cycloreversion could proceed in the pure hydrocarbon crystal. Once a [2+2] photocycloaddition reaction occurs for the spiro-DBCHT 1a-1c, changes not only in physical properties but also in the bond length of the 'core' $\mathrm{C}-\mathrm{C}$ bond should be observed. This paper describes how the reversible formation and scission of $\mathrm{C}-\mathrm{C}$ bonds in a single crystal can be induced by external stimulation of light and heat, accompanied by reversible expansion and contraction of the elongated $\mathrm{Csp}^{3}-\mathrm{Csp}^{3}$ bond and by a change of the HOMO level by ca. $1 \mathrm{eV}$.

\section{Results and Discussion}

According to the structures of $\mathbf{1 a - 1 \mathbf { c }},{ }^{[19]}$ two $\mathrm{DBCHT}$ units are well-overlapped due to $\pi-\pi$ interaction with a C-C distance of 3.163(3)-3.357(4) A between the vinylic carbons. Thus, we first photoirradiated $\mathrm{CHCl}_{3}$ solutions of $1 \mathrm{a}-1 \mathrm{c}$ at around $365 \mathrm{~nm}$, which is assigned to an absorption band of DBCHT units by time-dependent density functional theory (TD-DFT) calculations (Figure S11). As a result, [2+2] photocyclization proceeded quantitatively in all spiro-DBCHT 1a-1c to produce caged molecules 2a-2c (Scheme 1), which was monitored by UV/Vis
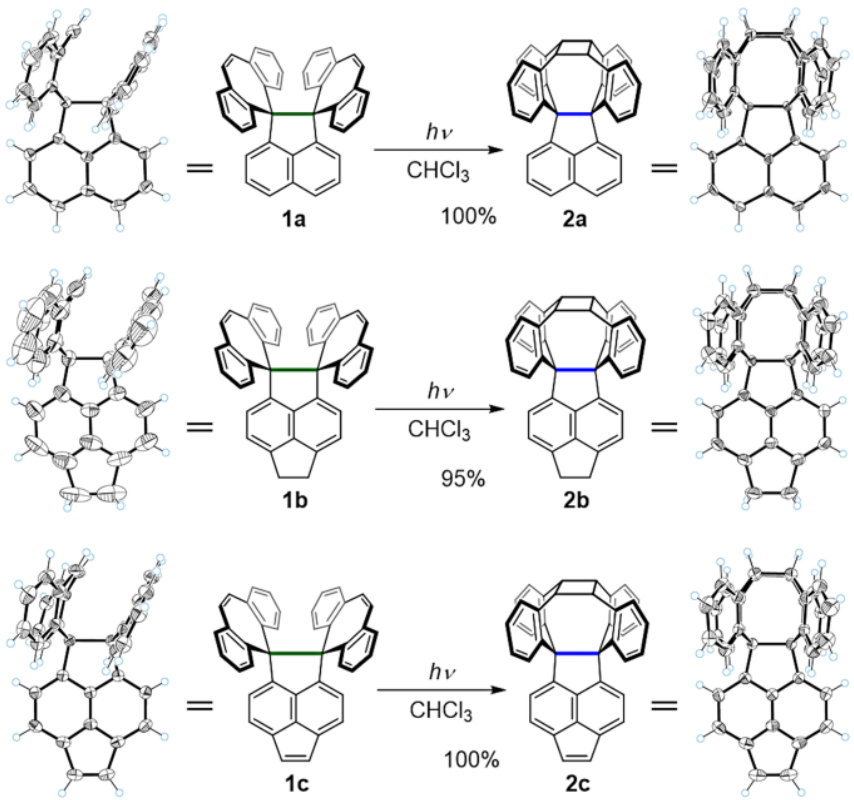

Scheme 1. Isolated yields of $2 a-2 c$ upon photoirradiation with a $375 \mathrm{~nm}$ lightemitting diode, and ORTEP drawings at $200 \mathrm{~K}$ of $\mathbf{1 a}-\mathbf{1 c}$ and $\mathbf{2 a - 2 c}$ (a)
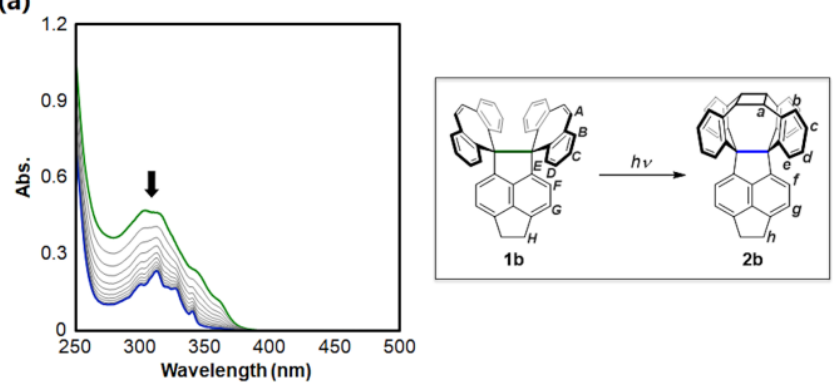

(b)

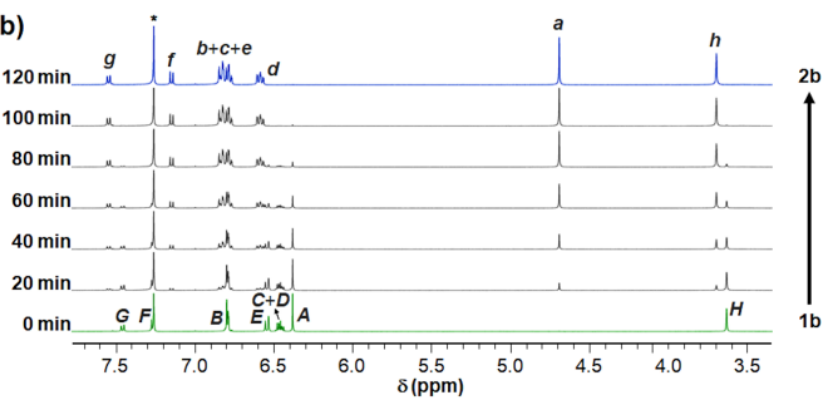

Figure 2. (a) Change in UV/Vis spectrum of $\mathbf{1 b}$ (green) to $\mathbf{2 b}$ (blue) in $\mathrm{CHCl}_{3}$ (every 5 min) and (b) change in ${ }^{1} \mathrm{H}$ NMR spectrum of $\mathbf{1} \mathbf{b}$ (green) to $\mathbf{2 b}$ (blue) in $\mathrm{CDCl}_{3}$ upon photoirradiation at $365 \mathrm{~nm}$ (Spectrofluorometer: $150 \mathrm{~W}$, Xe lamp, slit width: $10 \mathrm{~nm})$. The residual proton signal of the solvent $\left(\mathrm{CHCl}_{3}, \delta=7.26\right.$ ppm) is marked with an asterisk.

and NMR spectroscopies (Figures 2, S14, and S15). Cleavage of the cyclobutane ring in $\mathbf{2 a - 2 c}$ did not occur upon photoirradiation at any wavelength. Disappearance of cisstilbene moieties results not only in a blue-shift and hypochromic shift of the absorption band, but also in switching of the major chromophores to the acenaphthene ring which is located far from the cyclobutane ring. X-ray analyses revealed that $\mathbf{2 a - 2 c}$ adopt caged structures with a four-membered ring (Scheme 1). A remarkable point is that contraction of the central $\mathrm{C}-\mathrm{C}$ single bond by as much as $~ 5 \%$, from 1.720(2)-1.742(2), 1.773(3), and $1.7980(18) \AA$ for spiro-DBCHT 1a, 1b, and 1c to 1.676(6)1.678(6), 1.7133(16), and 1.7129(19) $\AA$ for caged molecules $2 \mathrm{a}$, $\mathbf{2 b}$, and $\mathbf{2 c}$, respectively, was observed at $200 \mathrm{~K}$ (Table 1). To verify the bonding nature of the contracted $\mathrm{C}-\mathrm{C}$ single bond, we investigated the stretching vibration of caged molecules $2 \mathrm{a}-\mathbf{2 c}$ by Raman spectroscopy with single crystals at $298 \mathrm{~K}$ to attain direct information of the bond strength. Observed Raman shifts corresponding to the central C-C bond were 653,646 , and 648 $\mathrm{cm}^{-1}$ for $\mathbf{2 a}, \mathbf{2 b}$, and $\mathbf{2 c}$, respectively, which are consistent with the simulated values $\left(663,653\right.$, and $\left.658 \mathrm{~cm}^{-1}\right)$ and $11 \%$ greater than those for 1a-1c (Table 1 and Figures S16-S18). The estimated force constant $\left(173.9 \mathrm{~N} \mathrm{~m}^{-1}\right)$ obtained as a second derivative of the energy to the bond length by DFT

Table 1. Central C-C bond lengths and Raman shifts for 1 and 2 determined by X-ray analyses (at $200 \mathrm{~K}$ ) and Raman spectroscopy (at $298 \mathrm{~K}$ ) with single crystals. Theoretically obtained HOMO and LUMO energy levels based on DFT calculations at the B3LYP/6-31G* level.

\begin{tabular}{|c|c|c|c|c|c|c|c|}
\hline & & $1 a$ & $2 a$ & $1 b$ & $2 b$ & 1c & 2c \\
\hline $\mathrm{C}-\mathrm{C}$ bond length $(\AA)$ & Expt. & $1.720(2)-1.742(2)$ & $1.676(6)-1.678(6)$ & $1.773(3)$ & $1.7133(16)$ & $1.7980(18)$ & $1.7129(19)$ \\
\hline Raman shift $\left(\mathrm{cm}^{-1}\right)$ & Expt. & 650 & 653 & 582 & 646 & 587 & 648 \\
\hline \multirow{2}{*}{ Energy level $(\mathrm{eV})$} & LUMO & -1.36 & -1.06 & -1.30 & -0.88 & -1.94 & -1.94 \\
\hline & HOMO & -5.29 & -5.58 & -5.24 & -5.35 & -5.33 & -5.77 \\
\hline
\end{tabular}


calculations (M06-2X/6-31G*) for $\mathbf{2 c}$ is 1.6 times as large as that for 1c $\left(108.3 \mathrm{~N} \mathrm{~m}^{-1}\right)$ (Figure S12).

Since HPEs with an elongated $\mathrm{C}-\mathrm{C}$ single bond can undergo two-electron oxidation to give bond-dissociated dicationic species, as found in dynamic redox (dyrex) systems, ${ }^{[39]}$ the redox potentials of spiro-DBCHT 1a-1c and caged molecules 2a-2c were measured by cyclic voltammetry in $\mathrm{CH}_{2} \mathrm{Cl}_{2}$ at ambient temperature (Figure $3 \mathrm{a}$ ). While two-electron oxidation occurs at lower potentials for the former with an expanded bond ( $E^{\mathrm{Ox}} / \mathrm{V}$ vs SCE: +0.93 for $\mathbf{1 a},+0.65$ for $\mathbf{1 b}$, and +0.57 and +0.69 for 1c), one-wave two-electron oxidation peaks appeared at much higher potentials for the latter with a contracted bond $\left(E^{\mathrm{ox}} / \mathrm{V}:+1.59\right.$ for $\mathbf{2 a},+1.36$ for $\mathbf{2 b}$, and +1.66 for $\mathbf{2 c}$ ) (Figures $3 a, d)$. Especially in $\mathbf{1 c} / \mathbf{2 c}$, we found the largest difference in potential of about $1.1 \mathrm{eV}$ before and after photocyclization. This change can be explained as follows: (i) the through-bond interaction that causes an increasing in the HOMO level would be maximized by expansion of the $\mathrm{C}-\mathrm{C}$ single bond ${ }^{[40,41]}$ and (ii) the coefficients in HOMO are located on the DBCHT unit and the elongated $\sigma$-bond in 1, whereas the coefficients are located on the acenaphthene, pyracene, or dihydropyracylene skeleton in 2 based on DFT calculations (Figures S10 and S13). On the other hand, two-electron reduction peaks were found in the far cathodic region due to cleavage of the elongated $\mathrm{C}-\mathrm{C}$ bond to give $3^{2+}$ or $\mathbf{4}^{2+}$ (dyrex behavior). It should be noted that reduction peaks in the voltammograms of $\mathbf{1}$ and $\mathbf{2}$ appear at almost the same potentials, indicating that the two-electron oxidation of caged molecules 2 could induce not only scission of the central $\mathrm{C}-\mathrm{C}$ bond but also cleavage of cyclobutane ring.

To gain further insight into the mechanism of three-bond scission in the oxidation of 2 , we conducted cyclic voltammetry at $195 \mathrm{~K}$ in $\mathrm{CH}_{2} \mathrm{Cl}_{2}$ using $\mathbf{2 b}$. As shown in Figures $3 b-d$, another reduction peak appeared at a less cathodic region $\left(E^{\mathrm{red}} / \mathrm{V}\right.$ : +0.99 ), which is far different from that in the reduction of $\mathbf{3} \mathbf{b}^{2+}$

(a)

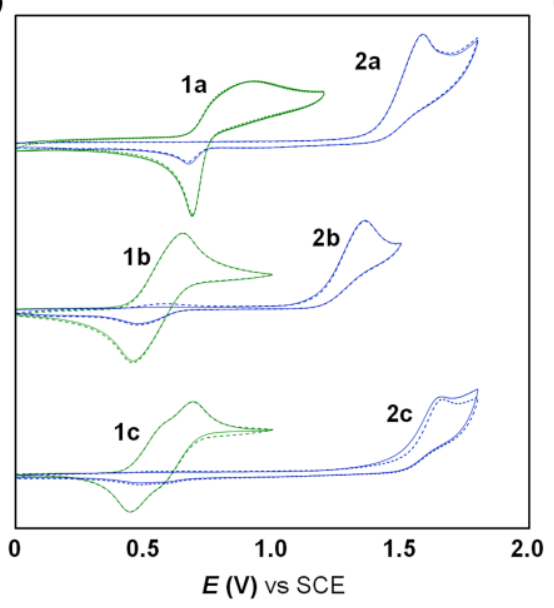

(b)

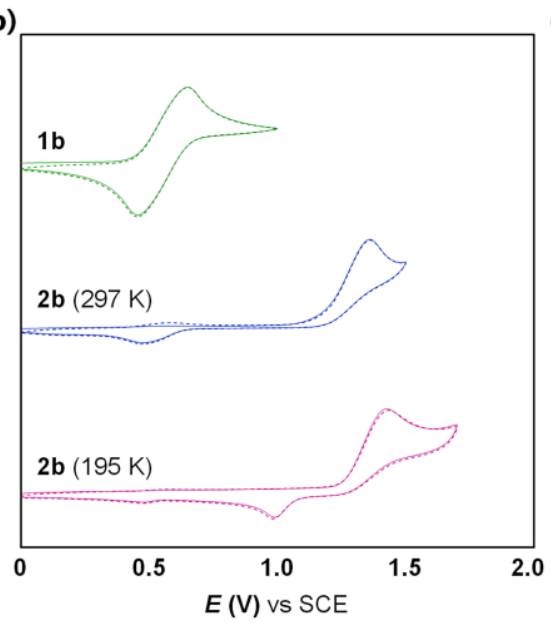

$\left(E^{\mathrm{red}} / \mathrm{V}:+0.46\right)$, and thus caged dication $4 \mathbf{b}^{2+}$ was generated by the oxidation of $\mathbf{2 b}$ through scission of the central $\mathrm{C}-\mathrm{C}$ bond even at low temperatures, whereas thermal cleavage of the cyclobutane ring of $\mathbf{4 b}^{2+}$ produces bond-dissociated dication $3 \mathbf{b}^{2+}$ at room temperature. Based on the voltammetric analysis, deeply colored dications $3 a^{2+}-3 c^{2+}$ were successfully isolated as stable $\left(\mathrm{SbCl}_{6}{ }^{-}\right)_{2}$ salts by treatment of spiro-DBCHT 1a-1c with two equivalents of $\left(4-\mathrm{BrC}_{6} \mathrm{H}_{4}\right)_{3} \mathrm{~N}^{+\cdot} \mathrm{SbCl}_{6}^{-}$in $\mathrm{CH}_{2} \mathrm{Cl}_{2}$, due to stabilization of the dibenzotropylium units (Scheme 2 and S19). Although formation of the same dication from caged molecules 2 was demonstrated by the electrochemical oxidation of $\mathbf{1} \mathbf{b} / \mathbf{2} \mathbf{b}$ and 1c/2c (Figures S20-S23), 2a-2c with lower HOMO levels need a stronger oxidant $\left(2,4-\mathrm{Br}_{2} \mathrm{C}_{6} \mathrm{H}_{3}\right)_{3} \mathrm{~N}^{+\cdot} \mathrm{SbCl}_{6}^{-}$in $\mathrm{CH}_{2} \mathrm{Cl}_{2}$ to give the same dications $3 \mathbf{a}^{2+-}-3 c^{2+}$. Thus, completely selective oxidation of $\mathbf{1 b}$ in a $1: 1$ mixture of $\mathbf{1} \mathbf{b}$ and $\mathbf{2} \mathbf{b}$ was achieved by using (4$\left.\mathrm{BrC}_{6} \mathrm{H}_{4}\right)_{3} \mathrm{~N}^{+\cdot} \mathrm{SbCl}_{6}^{-}$. This means that spiro-DBCHT 1 can be protected against oxidation by conversion into caged molecules 2 with a lower HOMO level.

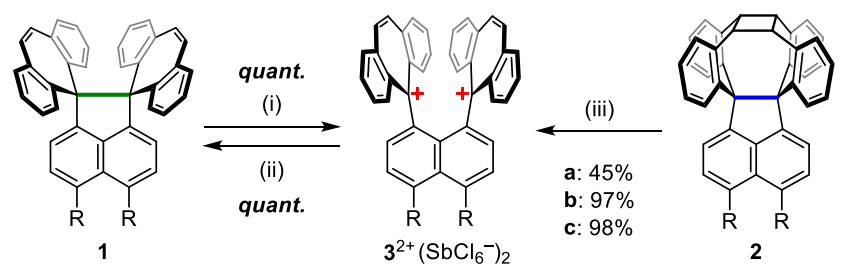

Scheme 2. Redox interconversion among 1, 2, and $3^{2+}\left(\mathrm{SbCl}_{6}^{-}\right)_{2}$. (i) (4$\left.\mathrm{BrC}_{6} \mathrm{H}_{4}\right)_{3} \mathrm{~N}^{+} \mathrm{SbCl}_{6}^{-}(2.0 \mathrm{eq}) / \mathrm{CH}_{2} \mathrm{Cl}_{2}$. (ii) $\mathrm{Zn}$ (excess) $/ \mathrm{CH}_{3} \mathrm{CN}$ or THF. (iii) $(2,4$ $\left.\mathrm{Br}_{2} \mathrm{C}_{6} \mathrm{H}_{3}\right)_{3} \mathrm{~N}^{+} \mathrm{SbCl}_{6}^{-}(2.0 \mathrm{eq}) / \mathrm{CH}_{2} \mathrm{Cl}_{2}$. [a $(\mathrm{R}=\mathrm{H}) ; \mathbf{b}\left(\mathrm{R}, \mathrm{R}=\mathrm{CH}_{2}-\mathrm{CH}_{2}\right) ; \mathbf{c}(\mathrm{R}, \mathrm{R}=$ $\mathrm{CH}=\mathrm{CH})]$

(d)

\begin{tabular}{|c|c|c|c|c|c|c|c|}
\hline \multirow{3}{*}{$\begin{array}{c}T(\mathrm{~K}) \\
E^{\mathrm{ox}}(\mathrm{V})\end{array}$} & $1 a$ & $2 a$ & $1 \mathrm{~b}$ & \multicolumn{2}{|c|}{$2 \mathrm{~b}$} & $1 \mathrm{c}$ & \multirow[t]{2}{*}{$2 c$} \\
\hline & \multicolumn{2}{|c|}{297} & \multicolumn{2}{|c|}{297} & \multirow{2}{*}{$\begin{array}{c}195 \\
+1.43(2 \mathrm{e})\end{array}$} & 297 & \\
\hline & $+0.93(2 \mathrm{e})$ & $+1.59(2 \mathrm{e})$ & $+0.65(2 e)$ & $+1.36(2 \mathrm{e})$ & & $+0.57,+0.69$ & $+1.66(2 \mathrm{e})$ \\
\hline & $3 a^{2+}$ & $3 a^{2+}$ & $3 b^{2+}$ & $3 b^{2+}$ & $4 b^{2+}$ & $3 c^{2+}$ & $3 c^{2+}$ \\
\hline$E^{\text {red }}(\mathrm{V})$ & $+0.69(2 \mathrm{e})$ & $+0.67(2 \mathrm{e})$ & $+0.46(2 e)$ & $+0.47(2 \mathrm{e})$ & $+0.99(2 e)$ & $+0.58,+0.44$ & $+0.59,+0.48$ \\
\hline
\end{tabular}

Figure 3. Cyclic voltammograms of (a) $\mathbf{1}$ and $\mathbf{2}$ at $297 \mathrm{~K}$ and (b) $\mathbf{1 b}$, $\mathbf{2 b}$ (at $297 \mathrm{~K}$ ), and $\mathbf{2 b}$ (at $195 \mathrm{~K}$ ) in $\mathrm{CH}_{2} \mathrm{Cl}_{2}$ containing $0.1 \mathrm{M} \mathrm{Bu}_{4} \mathrm{NBF}_{4}$ as a supporting electrolyte (scan rate $0.1 \mathrm{~V} \mathrm{~s}^{-1}$, Pt electrode). The second cycles are shown by a dotted line. (c) Mechanism of redox interconversion. (d) Redox potentials are summarized and peak potentials are shown as $E^{\circ \mathrm{x}}$ and $E^{\text {red. }}$. $\left.\mathbf{a}(\mathrm{R}=\mathrm{H}) ; \mathbf{b}\left(\mathrm{R}, \mathrm{R}=\mathrm{CH}_{2}-\mathrm{CH}_{2}\right) ; \mathbf{c}(\mathrm{R}, \mathrm{R}=\mathrm{CH}=\mathrm{CH})\right]$ 
(a)

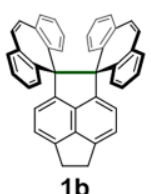

$\frac{h v(>390 \mathrm{~nm})}{\text { single crystal }}$

1b

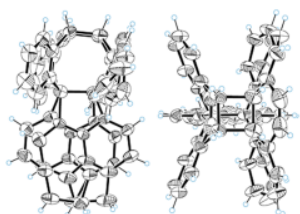

for $10 \mathrm{~h}$

$\mathbf{1 b} / \mathbf{2 b}=55 / 45$

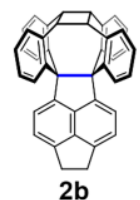

2b

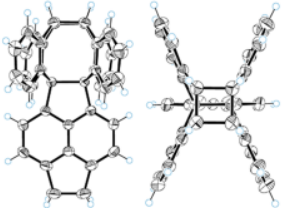

for $60 \mathrm{~h}$

$1 \mathrm{~b} / \mathbf{2 b}=0 / 100$

(b)

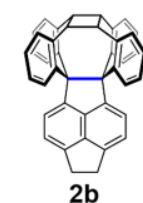

$\Delta(493 \mathrm{~K})$

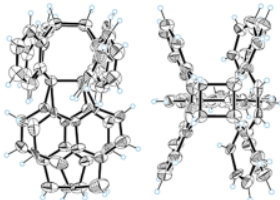

for $10 \mathrm{~min}$

$\mathbf{2 b} / \mathbf{1 b}=82 / 18$

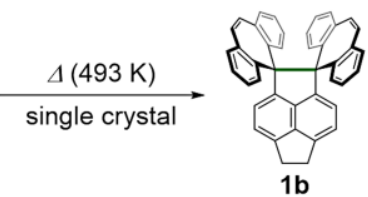

$1 b$

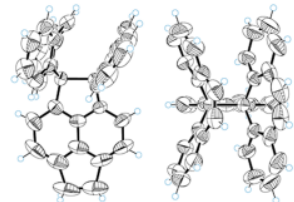

for $60 \mathrm{~min}$ $\mathbf{2 b} / \mathbf{1} \mathbf{b}=0 / 100$ (c)

\begin{tabular}{c|cccc}
\hline measured at $200 \mathrm{~K}$ & $\mathbf{1 b}$ & $\mathbf{1 b} / \mathbf{2 b}$ & $\mathbf{1 b} / \mathbf{2 b}$ & $\mathbf{2 b}$ \\
\hline Photoirradiation & - & $10 \mathrm{~h}$ & $60 \mathrm{~h}$ & - \\
\hline Ratio & 100 & $55 / 45$ & $0 / 100$ & 100 \\
\hline $\boldsymbol{a}(\mathrm{A})$ & $12.782(2)$ & $12.9352(3)$ & $13.26411(14)$ & $13.25273(12)$ \\
\hline $\boldsymbol{b}(\mathbf{A})$ & $9.228(2)$ & $9.05991(18)$ & $8.78016(8)$ & $8.78403(9)$ \\
\hline $\boldsymbol{c}(\mathbf{A})$ & $24.084(4)$ & $23.7724(4)$ & $23.6884(2)$ & $23.6979(2)$ \\
\hline $\boldsymbol{\beta}\left(^{\circ}\right)$ & $100.159(3)$ & $98.6273(16)$ & $97.1720(9)$ & $97.1488(8)$ \\
\hline $\boldsymbol{V}\left(\mathbf{A}^{3}\right)$ & $2796.2(8)$ & $2754.41(9)$ & $2737.19(5)$ & $2737.28(4)$ \\
\hline $\mathbf{C}-\mathbf{C}$ bond length $(\mathrm{A})$ & $1.773(3)$ & $1.738(3)$ & $1.7118(15)$ & $1.7133(16)$ \\
\hline $\boldsymbol{R} \mathbf{1}$ & 0.0633 & 0.0672 & 0.0411 & 0.0422 \\
\hline $\boldsymbol{w R 2}$ & 0.1968 & 0.1883 & 0.1099 & 0.1147 \\
\hline
\end{tabular}

(d)

\begin{tabular}{c|cccc}
\hline measured at $300 \mathrm{~K}$ & $\mathbf{2 b}$ & $\mathbf{2 b} / \mathbf{1 b}$ & $\mathbf{2 b} / \mathbf{1 b}$ & $\mathbf{1 b}$ \\
\hline Heating & - & $10 \mathrm{~min}$ & $60 \mathrm{~min}$ & - \\
\hline Ratio & 100 & $82 / 18$ & $0 / 100$ & 100 \\
\hline $\boldsymbol{a}(\mathrm{A})$ & $13.26469(12)$ & $13.1312(2)$ & $12.8016(3)$ & $12.79971(16)$ \\
\hline $\boldsymbol{b}(\mathrm{A})$ & $8.83221(9)$ & $8.93972(15)$ & $9.2206(3)$ & $9.22089(12)$ \\
\hline $\boldsymbol{c}(\mathrm{A})$ & $23.79279(19)$ & $23.8993(4)$ & $24.0574(7)$ & $24.0558(3)$ \\
\hline $\boldsymbol{\beta}\left(^{\circ}\right)$ & $97.2129(8)$ & $97.3675(17)$ & $99.953(3)$ & $100.0421(11)$ \\
\hline $\boldsymbol{V}\left(\mathrm{A}^{3}\right)$ & $2765.42(4)$ & $2782.36(8)$ & $2796.97(13)$ & $2795.68(6)$ \\
\hline $\mathbf{C}-\mathbf{C}$ bond length (A) & $1.7135(16)$ & $1.724(2)$ & $1.777(3)$ & $1.772(3)$ \\
\hline $\boldsymbol{R} \mathbf{1}$ & 0.0423 & 0.0559 & 0.0751 & 0.0879 \\
\hline $\boldsymbol{w R 2}$ & 0.1223 & 0.1727 & 0.2329 & 0.2601 \\
\hline & & & &
\end{tabular}

Figure 4. (a) Upon photoirradiation of a single crystal of $\mathbf{1 b}$ with $\lambda>390 \mathrm{~nm}$ for $10 \mathrm{~h}$ and $60 \mathrm{~h}$, the SCSC photocycloaddition reaction proceeded in respective yields of $45 \%$ and $100 \%$, which were determined by a single-crystal X-ray analysis at $200 \mathrm{~K}$. (b) When a single crystal of $2 \mathrm{~b}$ was heated at $493 \mathrm{~K}$ for 10 min and $60 \mathrm{~min}$, SCSC thermal cycloreversion proceeded in respective yields of $18 \%$ and $100 \%$, which were determined by a single-crystal X-ray analysis at 300 K. Thermal ellipsoids are shown at the $30 \%$ probability level for intermediates and the $50 \%$ probability level for completely converted samples. (c,d) The crystallographic data for $\mathbf{1} \mathbf{b}$ and $\mathbf{2 b}$ are summarized in the table.

By considering the similarity of the crystal packing and lattice parameters of $\mathbf{1} \mathbf{b}$ and $\mathbf{2} \mathbf{b}$, we envisaged that both the photocyclization of $\mathbf{1 b}$ and the thermal cycloreversion of $\mathbf{2} \mathbf{b}$ would proceed in a single-crystalline state. When a single crystal of $\mathbf{1 b}$ was photoirradiated at its absorption end so that the light can be penetrated into the deep inside of the crystal $(\lambda>390$ $\mathrm{nm}$ ) for $10 \mathrm{~h}$, caged molecule $\mathbf{2 b}$ was generated with maintaining single-crystallinity, and the proportion of $\mathbf{2} \mathbf{b}$ was as high as $45 \%$ as determined by a single-crystal X-ray analysis at $200 \mathrm{~K}$. This transformation is accompanied by contraction of the central C-C bond from 1.773(3) A to 1.738(3) A (Figures 4a,c). After photoirradiation of $\mathbf{1 b}$ for $60 \mathrm{~h}$, conversion to $\mathbf{2 b}$ was completed while maintaining single-crystallinity, where the contracted bond length $[1.7118(15) \AA]$ is essentially the same as that $[1.7133(16) \AA]$ in the recrystallized sample of $\mathbf{2 b}$. In addition, upon heating of a single crystal of $2 b$ at $493 \mathrm{~K}$ for $10 \mathrm{~min}$, thermal cleavage of the cyclobutane ring proceeded in $18 \%$ yield and thermal isomerization proceeded completely after heating for $60 \mathrm{~min}$, which was followed by single-crystal X-ray diffraction at $300 \mathrm{~K}$ (Figures $4 \mathrm{~b}, \mathrm{~d}$ ). As a result of the ring-opening of cyclobutane, the central $\mathrm{C}-\mathrm{C}$ bond was certainly expanded to the original value $[1.777(3) \AA]$, which is in good agreement with that $[1.772(3) \AA]$ in the recrystallized sample of $\mathbf{1 b}$, thanks to the outstanding stability of the long-bonded compound $\mathbf{1 b}$ at high temperature. These results show that reversible SCSC transformation occurred between $\mathbf{1 b}$ and $\mathbf{2} \mathbf{b}$, accompanied by unprecedented expansion and contraction of the elongated $\mathrm{C}-\mathrm{C}$ bond. Although single-crystallinity was not maintained for the pairs $\mathbf{1 a} / \mathbf{2 a}$ and $\mathbf{1 c} / \mathbf{2 c}$, quantitative [2+2] photocyclization and thermal cleavage of the cyclobutane ring were also achieved in the solid state (Figure S24).

We then could demonstrate that both spiro-DBCHT 1 and caged molecules 2 react with an oxidant to produce dication $3^{2+}$ in a solid state. When $\mathbf{1 b}$ was subjected to grinding with two equivalents of blue-colored $\left(4-\mathrm{BrC}_{6} \mathrm{H}_{4}\right)_{3} \mathrm{~N}^{+} \mathrm{SbCl}_{6}{ }^{-}$, the color changed to deep purple with the formation of dicationic dye $3 \mathbf{b}^{2+}$, which was confirmed by the appearance of characteristic IR absorptions assigned to $3 \mathbf{b}^{2+}\left(\mathrm{SbCl}_{6}^{-}\right)_{2}$ (e.g. 1601 and $1385 \mathrm{~cm}^{-1}$ ) and the resulting amine (e.g. 1486 and $1311 \mathrm{~cm}^{-1}$ ) (Figures $5 a, d)$. Moreover, grinding of $\mathbf{2 b}$ with two equivalents of greencolored $\left(2,4-\mathrm{Br}_{2} \mathrm{C}_{6} \mathrm{H}_{3}\right)_{3} \mathrm{~N}^{+} \cdot \mathrm{SbCl}_{6}{ }^{-}$smoothly led to the formation of a deep purple powder of dication salt $3 \mathbf{b}^{2+}\left(\mathrm{SbCl}_{6}{ }^{-}\right)_{2}$, where threebond scission proceeded in a solid state (Figures $5 \mathrm{~b}, \mathrm{e}$ ). Additionally, upon grinding of $3 \mathbf{b}^{2+}\left(\mathrm{SbCl}_{6}{ }^{-}\right)_{2}$ with an excess amount of $\mathrm{Zn}$ powder, $\mathbf{3 b}^{2+}$ underwent two-electron reduction to give long-bonded $\mathbf{1 b}$ (Figures $5 \mathrm{c}, \mathrm{f}$ ). This is the first example of flexible $\mathrm{C}-\mathrm{C}$ bond exhibiting the reversible expansion, contraction, formation, and scission of a $\mathrm{Csp}^{3}-\mathrm{Csp}^{3}$ single bond in a simple organic compound, especially in a pure hydrocarbon.

\section{Conclusion}

We have demonstrated that photo- and thermal isomerization between spiro-DBCHT $\mathbf{1}$ and caged molecules $\mathbf{2}$ proceeded quantitatively in a solid state, where the reversible formation and 
(a)

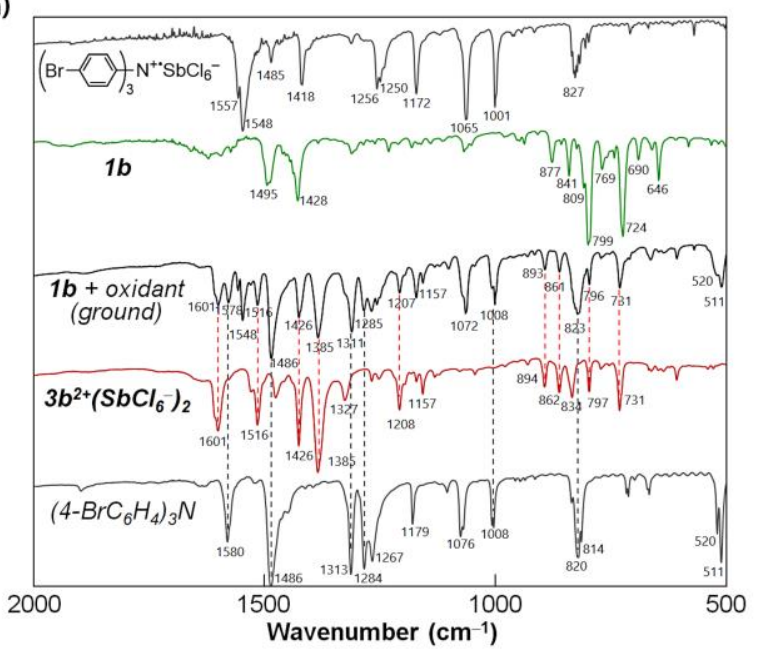

(c)

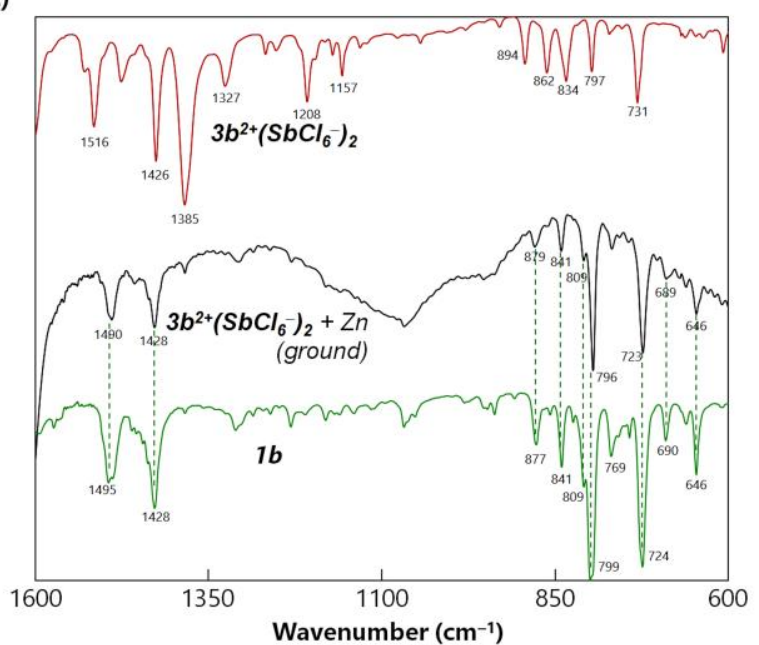

(b)

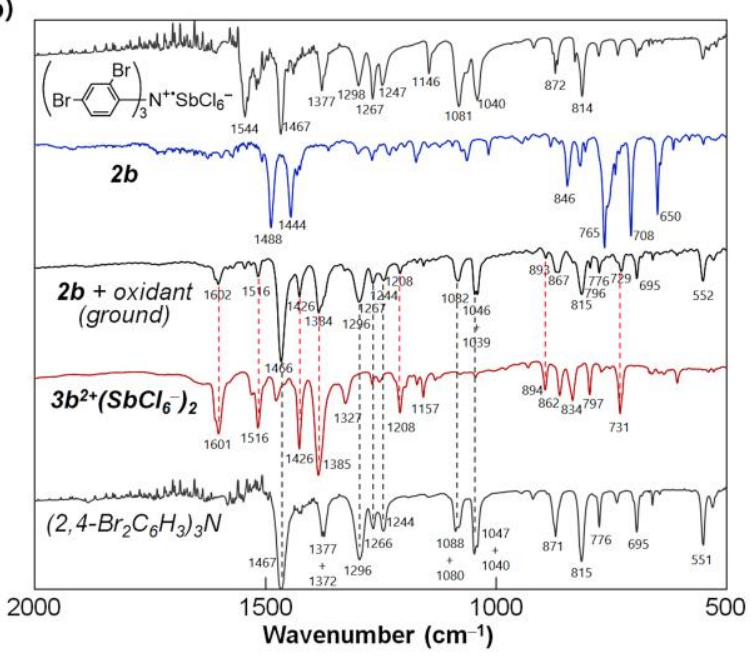

(d)

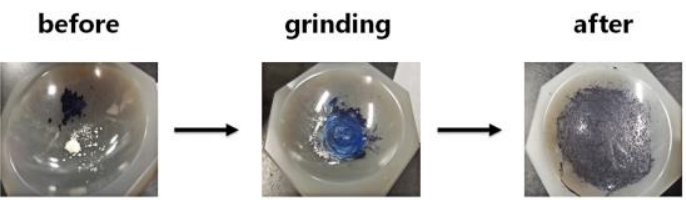

(e)

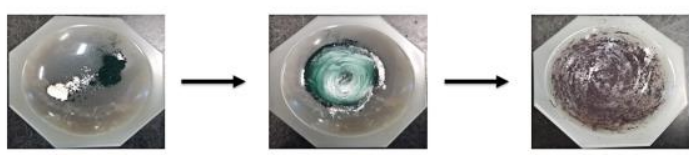

(f)

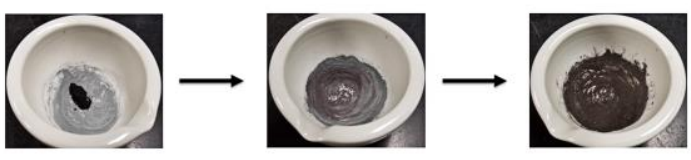

Figure 5. (a) Solid-state oxidation of $\mathbf{1 b}$ with two equivalents of $\left(4-\mathrm{BrC}_{6} \mathrm{H}_{4}\right)_{3} \mathrm{~N}^{+\cdot} \mathrm{SbCl}_{6}{ }^{-}$was confirmed by IR spectroscopy. (b) Solid-state oxidation of $\mathbf{2 b}$ with two equivalents of $\left(2,4-\mathrm{Br}_{2} \mathrm{C}_{6} \mathrm{H}_{3}\right)_{3} \mathrm{~N}^{++} \mathrm{SbCl}_{6}^{-}$as a stronger oxidant was confirmed by IR spectroscopy. (c) Solid-state reduction of $\left.3 \mathbf{b}^{2+}\left(\mathrm{SbCl}_{6}\right)_{2}\right)_{2}$ with an excess amount of $\mathrm{Zn}$ powder was confirmed by IR spectroscopy. Photographs of mechano-oxidation of (d) $\mathbf{1 b}$ with $\left(4-\mathrm{BrC}_{6} \mathrm{H}_{4}\right)_{3} \mathrm{~N}^{+} \mathrm{SbCl}_{6}^{-}$and (e) $\mathbf{2 b}$ with $(2,4-$ $\left.\mathrm{Br}_{2} \mathrm{C}_{6} \mathrm{H}_{3}\right)_{3} \mathrm{~N}^{+} \mathrm{SbCl}_{6}^{-}$, and (f) mechano-reduction of $3 \mathbf{b}^{2+}\left(\mathrm{SbCl}_{6}{ }^{-}\right)_{2}$ with an excess amount of $\mathrm{Zn}$ powder.

scission of two C-C bonds were accompanied by expansion and contraction of the central $\mathrm{C}-\mathrm{C}$ bond. Since formation of the cyclobutane ring and contraction of the $\mathrm{C}-\mathrm{C}$ bond induce lowering of the HOMO level, oxidative properties can be deactivated/activated by light/heat. Caged molecules 2 generated by the photoirradiation of spiro-DBCHT 1 undergo two-electron oxidation to transiently produce bond-dissociated dications $4^{2+}$ followed by thermal cleavage of the cyclobutane ring to give stable dications $3^{2+}$. An elongated $\mathrm{C}-\mathrm{C}$ bond was reformed by two-electron reduction of dications $3^{2+}$, resulting in the formation of original spiro-DBCHT 1. Notably, all of these processes can proceed in a solid state. This paper provides a new perspective on $\mathrm{C}-\mathrm{C}$ bonds that exhibit reversible expansion, contraction, formation, and scission. Thus hydrocarbons that contain a 'flexible' $\mathrm{C}-\mathrm{C}$ bond could be promising candidates for the development of functional materials, whose crystals, films, or polymers can respond to the external stimuli such as light and heat with anisotropic expansion and contraction of the matter as well as reversible switching of oxidative properties.

\section{Acknowledgements}

This work was supported by JSPS KAKENHI Grant Numbers JP19K15528, JP20H02719, and JP20K21184, and JSPS Grantin-Aid for Research Fellow JP19J20831. Y.I. acknowledges Toyota Riken Scholar and The NOVARTIS Foundation (Japan) for the Promotion of Science. T.Sh. is grateful for the Ministry of Education, Culture, Sports, Science and Technology through the Program for Leading Graduate Schools (Hokkaido University "Ambitious Leader's Program").

Keywords: long bond $\cdot$ single-crystalline reaction $•$ cyclization • thermal cycloreversion $\cdot$ redox chemistry

[1] M. A. Majewski, M. Stępień, Angew. Chem. Int. Ed. 2019, 58, 86-116; Angew. Chem. 2019, 131, 90-122.

[2] M. Saito, H. Shinokubo, H. Sakurai, Mater. Chem. Front. 2018, 2, 635661.

[3] S. H. Pun, Q. Miao, Acc. Chem. Res. 2018, 51, 1630-1642. 
[4] T. Hosokawa, Y. Takahashi, T. Matsushima, S. Watanabe, S. Kikkawa, I. Azumaya, A. Tsurusaki, K. Kamikawa, J. Am. Chem. Soc. 2017, 139 18512-18521.

[5] Q. Wang, P. Hu, T. Tanaka, T. Y. Gopalakrishna, T. S. Herng, H. Phan, W. Zeng, J. Ding, A. Osuka, C. Chi, J. Siegel, J. Wu, Chem. Sci. 2018 9, 5100-5105.

[6] Y. Nakakuki, T. Hirose, K. Matsuda, J. Am. Chem. Soc. 2018, 140, 15461-15469

[7] Y. Xiao, J. T. Mague, R. H. Schmehl, F. M. Haque, R. A. Pascal, Angew. Chem. Int. Ed. 2019, 58, 2831-2833; Angew. Chem. 2019, 131 2857-2859.

[8] Y. Hu, G. M. Paternò, X.-Y. Wang, X.-C. Wang, M. Guizzardi, Q. Chen D. Schollmeyer, X.-Y. Cao, G. Cerullo, F. Scotognella, K. Müllen, A Narita, J. Am. Chem. Soc. 2019, 141, 12797-12803.

[9] G. Povie, Y. Segawa, T. Nishihara, Y. Miyauchi, K. Itami, Science 2017, 356, 172-175.

[10] K. Y. Cheung, S. Gui, C. Deng, H. Liang, Z. Xia, Z. Liu, L. Chi, Q. Miao, Chem 2019, 5, 838-847.

[11] Y. Segawa, M. Kuwayama, Y. Hijikata, M. Fushimi, T. Nishihara, J. Pirillo, J. Shirasaki, N. Kubota, K. Itami, Science 2019, 365, 272-276.

[12] Y. Ni, T. Y. Gopalakrishna, H. Phan, T. Kim, T. S. Herng, Y. Han, T. Tao, J. Ding, D. Kim, J. Wu, Nat. Chem. 2020, 12, 242-248.

[13] M. Rickhaus, M. Jirasek, L. Tejerina, H. Gotfredsen, M. D. Peeks, R. Haver, H.-W. Jiang, T. D. W. Claridge, H. L. Anderson, Nat. Chem. 2020, 12, 236-241.

[14] T. Mio, K. Ikemoto, S. Sato, H. Isobe, Angew. Chem. Int. Ed. 2020, 59, 6567-6571; Angew. Chem. Int. Ed. 2020, 132, 6629-6633.

[15] T. A. Schaub, E. A. Prantl, J. Kohn, M. Bursch, C. R. Marshall, E. J. Leonhardt, T. C. Lovell, L. N. Zakharov, C. K. Brozek, S. R. Waldvogel, S. Grimme, R. Jasti, J. Am. Chem. Soc. 2020, 142, 8763-8775.

[16] P. R. Schreiner, L. V Chernish, P. A. Gunchenko, E. Y. Tikhonchuk, H. Hausmann, M. Serafin, S. Schlecht, J. E. P. Dahl, R. M. K. Carlson, A. A. Fokin, Nature 2011, 477, 308-311.

[17] S. Kammermeier, P. G. Jones, R. Herges, Angew. Chem. Int. Ed. Engl. 1997, 36, 1757-1760; Angew. Chem. 1997, 109, 1825-1828.

[18] K. Tanaka, N. Takamoto, Y. Tezuka, M. Kato, F. Toda, Tetrahedron 2001, 57, 3761-3767.

[19] Y. Ishigaki, T. Shimajiri, T. Takeda, R. Katoono, T. Suzuki, Chem 2018 4, 795-806.

[20] J. Li, R. Pang, Z. Li, G. Lai, X.-Q. Xiao, T. Müller, Angew. Chem. Int. Ed. 2019, 58, 1397-1401; Angew. Chem. 2019, 131, 1411-1415.

[21] J. Luo, K. Song, F. long Gu, Q. Miao, Chem. Sci. 2011, 2, 2029-2034.

[22] Y. Ishigaki, Y. Hayashi, T. Suzuki, J. Am. Chem. Soc. 2019, 141, 18293-18300.

[23] M. Pillekamp, W. Alachraf, I. M. Oppel, G. Dyker, J. Org. Chem. 2009 , 74, 8355-8358.

[24] B. L. Feringa, J. Org. Chem. 2007, 72, 6635-6652.

[25] M. Irie, T. Fukaminato, K. Matsuda, S. Kobatake, Chem. Rev. 2014, 114, 12174-12277.

[26] V. García-López, D. Liu, J. M. Tour, Chem. Rev. 2020, 120, 79-124.

[27] M. Baroncini, S. Silvi, A. Credi, Chem. Rev. 2020, 120, 200-268.

[28] P. Ravat, T. Šolomek, D. Häussinger, O. Blacque, M. Juríček, J. Am. Chem. Soc. 2018, 140, 10839-10847.

[29] C. L. Fleming, S. Li, M. Grøtli, J. Andréasson, J. Am. Chem. Soc. 2018 140, 14069-14072.

[30] T. Yang, Y. Wang, X. Liu, G. Li, W. Che, D. Zhu, Z. Su, M. R. Bryce, Chem. Commun. 2019, 55, 14582-14585.

[31] P. Lentes, E. Stadler, F. Röhricht, A. Brahms, J. Gröbner, F. D. Sönnichsen, G. Gescheidt, R. Herges, J. Am. Chem. Soc. 2019, 141, 13592-13600

[32] N.-Y. Li, J.-M. Chen, X.-Y. Tang, G.-P. Zhang, D. Liu, Chem. Commun. 2020, 56, 1984-1987.

[33] K. Novak, V. Enkelmann, G. Wegner, K. B. Wagener, Angew. Chem. Int. Ed. Engl. 1993, 32, 1614-1616; Angew. Chem. 1993, 105, 16781680.

[34] G. K. Kole, T. Kojima, M. Kawano, J. J. Vittal, Angew. Chem. Int. Ed. 2014, 53, 2143-2146; Angew. Chem. Int. Ed. 2014, 126, 2175-2178.

[35] N.-Y. Li, D. Liu, B. F. Abrahams, J.-P. Lang, Chem. Commun. 2018, 54, 5831-5834.
[36] G. Pahari, B. Bhattacharya, C. M. Reddy, D. Ghoshal, Chem. Commun 2019, 55, 12515-12518.

[37] I. E. Claassens, L. J. Barbour, D. A. Haynes, J. Am. Chem. Soc. 2019 $141,11425-11429$.

[38] J. Zhang, J. Li, X. Feng, M. Kong, Z. Hu, Y.-X. Zheng, Y. Song, Chem Commun. 2019, 55, 12873-12876.

[39] T. Suzuki, H. Tamaoki, J. Nishida, H. Higuchi, T. Iwai, Y. Ishigaki, K. Hanada, R. Katoono, H. Kawai, K. Fujiwara, T. Fukushima, in Organic Redox Systems: Synthesis, Properties and Applications, Chapter 2, Wiley, 2015, 13-37.

[40] R. Hoffmann, Acc. Chem. Res. 1971, 4, 1-9.

[41] Y. Ishigaki, Y. Hayashi, K. Sugawara, T. Shimajiri, W. Nojo, R. Katoono, T. Suzuki, Molecules 2017, 22, 1900. 


\section{Entry for the Table of Contents}

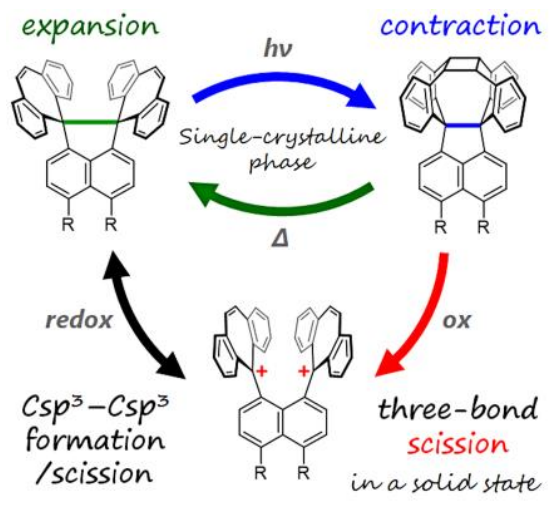

Flexible $\mathrm{C}-\mathrm{C}$ bond! Reversible expansion and contraction of a $\mathrm{Csp}^{3}-\mathrm{Csp}^{3}$ single bond triggered by light/heat were certainly visualized by single crystal X-ray analyses. In combination with redox chemistry, reversible interconversion was demonstrated between long bonded neutral species and stable dication, accompanied by $\mathrm{C}-\mathrm{C}$ bond formation and scission. All processes can proceed in a solid state.

Institute and researcher Twitter usernames: Twitter usernames: lab (@Yuuichi_Hokudai) and Yusuke Ishigaki (@ysk_isgk) 